\title{
Strategic Alliance with Competitors in the Electric Vehicle Market: Tesla Motor's Case
}

\author{
Taesu Cheong, ${ }^{1}$ Sang Hwa Song, ${ }^{2}$ and Chao $\mathrm{Hu}^{3}$ \\ ${ }^{1}$ School of Industrial Management Engineering, Korea University, Seoul 136713, Republic of Korea \\ ${ }^{2}$ Graduate School of Logistics, Incheon National University, Incheon 406130, Republic of Korea \\ ${ }^{3}$ Lee Kong Chian School of Business, Singapore Management University, Singapore 178899 \\ Correspondence should be addressed to Sang Hwa Song; songsh@incheon.ac.kr
}

Received 8 October 2015; Accepted 8 November 2015

Academic Editor: Paulina Golinska

Copyright (c) 2016 Taesu Cheong et al. This is an open access article distributed under the Creative Commons Attribution License, which permits unrestricted use, distribution, and reproduction in any medium, provided the original work is properly cited.

We investigate how the choice of coopetition of the simultaneous pursuit of collaboration and competition dynamically impacts both the participating firms and also the other self-developing ones in the same market. A conceptual framework of mathematical models obtained from the arguments and insights in the literature is used to undertake an in-depth study through a multiperiod analysis from 2013 to 2020 of an exemplar case of coopetition, the two concurrently ongoing coopetition partnerships in the US electric vehicle (EV) market, the Tesla Motors-Daimler AG alliance and the Tesla Motors-Toyota alliance and the other firms which are not involved in coopetition.

\section{Introduction}

In the modern business world, the concept that "business is war" is becoming outdated. For example, the conventional strategies of defending market share, locking up customers, and offering lower prices may impede competitors entering the market, but, at the same time, they may burden companies by increasing operation and investment costs.

Coopetition is a business strategy based on the simultaneous combination of cooperation and competition, and it allows all participating firms to be better off, in terms of bigger market shares, higher profits, and technical improvements, depending on their particular interests and goals. Unlike a zero-sum game in which the winner takes all and the loser gets nothing, coopetition is, in fact, a type of positive-sum game in which the final gains of each player are greater than what each player initially brings to the game. As illustrated in Brandenburger and Nalebuff [1], coopetition can lead to mutual success in two ways, the vertical or horizontal supply chain model (see Figure 1). A vertical supply chain coopetition is a temporary alliance formed between a supplier and an assembler. The substantial demand for an assembler's product in the retail market results in more orders of parts from suppliers [2]. For example, the success of Microsoft is desirable to Intel, because Intel can sell more chips, and Intel producing a more sophisticated chip allows Microsoft in turn to design more powerful software and cater their products to more customers. A horizontal supply chain coopetition is a game where competitors operate in the same retail market [1]. It is cooperation when a firm offers lowercost work-in-process parts to others, and competition when those same firms have to compete with each other for customers' attention in the retail market. For example, Apple Inc. is continuously ordering microprocessors manufactured by Samsung Electronics Co. for its iPhone series, but the two companies have had conflicts and even sued each other over the patent rights of their phone designs $[3,4]$.

Moreover, coopetition becomes a more critical opportunity in industries requiring high technology or heavy entry fees [5]. Challenges such as shortened product life cycles, the necessity of heavy R\&D investments, and the compulsory initial payment can hardly be tackled by an individual firm because of the difficulty of liquidity management and the shortage of talented employees [6]. Although a higher standard of technology leads to a stronger competitive advantage, it is not always a wise choice to develop those innovative reforms alone since such research projects may take an unpredictable length of time and even fail to lead to a 


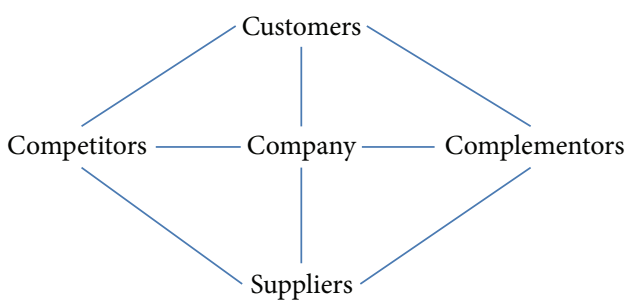

FIGURE 1: Value net [1].

profitable commercial model, especially, when similar technologies have been implemented by other competitors [7]. It may be better for a firm to use coopetition, establishing a strategic partnership with another firm that has the key technology first and then creating an own version through the learning-by-doing effect. For example, after having partnered with Amazon.com and leveraging Amazon's innovative IT-based supply chain and online store for seven years, Borders turned to developing its own online store once it had acquired sufficient knowledge and experience. Such an example of coopetition illustrates a mutual win-win outcome: Amazon.com has earned substantial payments by offering their advanced online system to Borders whereas Borders has shortened the process of entering the online market by learning from Amazon.com [8]. Hence, with the understanding that there is a possibility of allying with competitors as temporary complementors, coopetition means that companies may simultaneously play two contrasting roles in relation to each other: (i) complementors in making markets and (ii) competitors in dividing up markets. For a sufficiently high expectation of increased market share, companies, making rational choices, would consider agreeing to form temporary alliances with competitors. However, such a kind of peace only has a partial influence on the market in which only a portion of firms are interested in coopetition, and it is actually only a truce in that it will not last forever. Therefore, there are several concerns bearing on the decisions of whether and how to enter coopetition including the following: what the right timing of cooperative alliance formation and discontinuation would be, how to choose alliances wisely in terms of quality and quantity, and how other firms which are not participating in the cooperation will respond.

In this paper, we evaluate the effects of horizontal coopetition in an oligopolistic market, where a low-cost firm offers work-in-process parts to high-marginal-cost firms by signing temporary contracts, which can be optimized through consideration of the cost incentives, costs of cooperation, and the possible learning-by-doing effect. Furthermore, based on the multiperiod model, we examine how the decision making on coopetition affects dynamic alliance formation and impacts outsiders. A case in the US electric vehicle (EV) market is specifically examined. Transportation accounts for 30 percent of US greenhouse gas (GHG) emissions and five percent of global emissions in 2010. GHG emissions from on-road vehicles accounted for 79 percent of transportation emissions, and 59 percent were from light-duty vehicles, which include passenger cars and pick-up trucks [9]. Hence, transportation reformation becomes essential to slow down the expanding fuel economy. Compared to traditional solutions such as carbon pricing, higher tax, and vehicle quota control to discourage customers' desire for internal combustion cars, a better alternative is to promote EVs, which represent a perfect complement to internal combustion vehicles. Without causing any inconvenience or reducing people's transportation efficiencies, EVs are designed for more efficient energy usage while providing similar services to customers as internal combustion vehicles do. In general, the drive efficiency for an $\mathrm{EV}$ is $88 \%$, meaning that $88 \%$ of the energy stored in EV's batteries is converted into mechanical energy, whereas an internal combustion car can only perform the conversion process with up to $35 \%$ efficiency [10]. Although the electrical energy consumed by EVs is currently generated by power stations, which have only $30-45 \%$ conversion efficiencies from fossil fuels to electricity [11], by having a no-worse energy efficiency compared to that of internal combustion vehicles, EVs allow power stations to store carbon dioxide and other GHGs in a better, centralized way and open the possibility of replacing the forms of raw energy used to generate electricity. Currently, Tesla Motors Inc., a California-based EV manufacturer, also manufactures electric powertrain components. Tesla's strategic approach to increase the number of varieties of EVs available to mainstream consumers includes the following:

(i) Selling its own vehicles in a growing number of company-owned showrooms and online.

(ii) Selling patented electric powertrain components to other automakers, including Daimler and Toyota.

(iii) Serving as a catalyst and positive example to other automakers, demonstrating that there is pent-up consumer demand for vehicles that have good performance as well as efficiency.

Unlike many traditional car manufacturers, Tesla operates as an original equipment manufacturer (OEM) for EV powertrain components, which other automakers may purchase and retail under their own brand names. Tesla has confirmed partnerships with two other automakers, Daimler and Toyota. At the end of 2012, Tesla had entered into two partnership contracts, one regarding the Mercedes-Benz Smart Fortwo E-Cell [12] and the other regarding the Toyota RAV4 [13]. Hence, the methodology of coopetition can be used to bargain the fixed cost and unit powertrain component cost between Tesla and Daimler/Toyota, influence the future sales of allied firms and outsiders such as GM and Ford, and predict how and when the learning-by-doing effect will foreshorten and finally end temporary strategic partnerships.

By analyzing the concomitant problems above, we intend to address the following issues: we (1) quantify coopetition strategies (Tesla-Daimler alliance and Tesla-Toyota alliance) to estimate values of variables including coopetition contract payments, unit part payments, and monitoring costs based on the mathematical models, (2) forecast the possible outcomes for each individual firm in the US EV market in each period under the two concurrently ongoing coopetitions, (3) anticipate the effect of coopetition on outsider firms in the same market, and more importantly (4) examine the proper timing 
to cease coopetition partnerships by considering the learning curve effects so that allied firms can get the most desirable trade-off.

The remainder of this paper is organized as follows: Section 2 provides literature reviews and discusses our contributions to the existing literature. Section 3 presents a mathematical model reflecting the coopetition setting in the EV market under consideration. In Section 4, based on the model proposed in Section 3, we examine the Tesla coopetition effects in the US EV market over the single period and multiple periods. Section 5 summarizes our major findings in this case study with managerial implications and concludes.

\section{Literature Review}

2.1. General Approach of Coopetition. Given that more than $50 \%$ of cooperative relations and activities are built by and conducted between firms in the same market, in which the firms usually treat each other as competitors [14], such frequent and unique interfirm strategies in which competition and cooperation occur concurrently have often been the subject of diverse thought and opinions in the literature. Brandenburger and Nalebuff [1] generalize coopetition as a complementary relationship between firms, illustrating that a supporting third firm can multiply the market share of competitors who are cooperating with them with examples of the success shared between computer manufacturers and software producers. On the other hand, a more narrowly defined coopetition, a firm-to-firm strategy in which simultaneous collaboration and competition are involved, is raised by Bengtsson and Kock [15]. A firm would handle complex relationships with its competitors, which would vary at different stages. For example, about manufacturing, a step far from customers, firms would cooperate, whereas about sales strategies firms would compete for more interaction with customers. Recently, Pathak et al. [16] investigate coopetition dynamics at the supply network level over time as the evolution of the appearance and expiration of ties among firms in a market.

\subsection{Impact of Coopetition on Technology Innovation. When} it comes to technology and innovation, partnerships and cooperation actually allow firms access to the acquisition and leveraging of resources essential for pursuing innovation, avoiding high risks and heavy investments and improving the chances of obtaining positive innovation outcomes [17, 18]. Acknowledging that allying with high-tech firms to gain advanced experience, despite cooperating with competing firms in doing so, is essential for product innovation in today's fast-changing markets [19], Daimler and Toyota have been cooperating with Tesla, which possesses the key technology of low-cost and efficient powertrain parts. Thereby they can learn about and employ this important technology in the EV market in the first place and develop more advanced powertrain prototypes together with Tesla thereafter. A successful analysis of coopetition between technological tycoons has been made by Gnyawali and Park [7]. Their research combined theoretical analysis and a real case study regarding coopetition about next-generation TV between Samsung Electronics and Sony Corporation and clearly shows how coopetition can be useful for tackling technological barriers, creating mutual profits, and improving technological innovations. However, the qualified approval of coopetition concepts reached by fitting historical data from a completed coopetition case to theories is not strong enough to predict the outcomes of future or even on-going coopetition. Hence, a scientific methodology and a mathematical model should be developed to anticipate the possible consequences of coopetition between Tesla and Daimler/Toyota. Granot and Yin [20] and Nagarajan and Sošić [21], on the other hand, have implemented a quantitative methodology to test and study the cooperation of competing firms in a common market. However, their study only covered two allied firms involved in coopetition and ignored the impacts of such coopetition on outsiders in the market. Zhang and Frazier [22] developed an advanced model based on Granot and Yin [20], by assuming a market where player 1 and player 2 form a temporary coopetition whereas player 3, an outsider, expands its business alone, and asserted that although coopetition may generate a mutual win-win outcome, the conflicts, in terms of the costly negotiation of cooperation payments and severe monitoring of operational costs until product delivery, may also intangibly benefit outsiders. Although Zhang and Frazier [22] provided a practical approach to coopetition in the EV market, they failed to consider a concurrent multicoopetition scenario in the EV market, as has developed, in which Tesla builds strategic partnerships with Daimler and Toyota simultaneously.

\section{Model}

In this section, we present mathematical models based on the arguments and insights in the literature to analyze the coopetition case of two concurrently ongoing coopetition partnerships, the Tesla Motors-Daimler AG alliance and Tesla Motor-Toyota alliance, in the US electric vehicle (EV) market and particularly how it influences the performance of the firms in that market.

3.1. Assumptions. In this study, we consider four players including Tesla in the EV market coopetition:

(i) Firm 1 (Tesla) offers high-tech powertrain components to high-marginal-cost firms like Daimler and Toyota.

(ii) Firms 2 (Daimler) and 3 (Toyota) have substantial vehicle market shares but are new in the EV market.

(iii) Firm 4 representing any of a group of outsiders, including GM and Ford, wishes to expand the market and improve its EV production by itself.

Given the model setting with four players in the EV market, we have the following assumptions:

(1) There is the competition amongst the three firms, in addition to with a group of outsiders (refer to Section 4).

(2) Perfect information exists in the EV market, so firms know their competitors' actions clearly. 
(3) Each firm in this study can produce one unique EV series only.

(4) Only firms 2 and 3 (i.e., Daimler and Toyota) can form temporary alliances with Tesla, and firm 4 representing the outsiders is only allowed to expand its market share alone and does not participate in any deal in the alliance.

(5) Product substitutabilities of firm $i(i=2,3,4)$ with respect to Tesla (firm 1 ) are only considered (i.e., there are no substitution effects among firms 2, 3, and 4).

(6) Tesla's powertrain components are treated as the topnotch product that all other firms wish to achieve.

(7) Before taking the learning-by-doing effect into account, firms 2 and 3 can only choose between purchasing powertrain components from Tesla or breaking their alliances and then producing the powertrain components by themselves.

3.2. Formulation. In this section, we present the model of the coopetition between Tesla and three firms. Let $a$ be the total market size (i.e., the total volume of the EV market). We let $\delta_{i}$ be the product substitutability of firm $i$ ( $i=$ $2,3,4)$ with respect to Tesla (firm 1 ). By using the degree of product substitutability, the demand function $q_{i}\left(p_{i}, p_{-i}\right)$ can be defined as

$$
q_{i}=a-p_{i}+\sum_{j \neq i} \delta_{j} p_{j}, \quad i=1,2,3,4
$$

according to Vives [23] where $p_{i}$ is the price of an EV of firm $i, p_{-i}$ is the prices of all other firms except $i$, and $q_{i}$ is the quantity (demand) of EVs sold by firm $i$.

Let $x_{j}(j=2,3,4)$ be the decision variable concerning whether to make an alliance relationship with Tesla so that $x_{2}, x_{3} \in\{0,1\}$ and $x_{4}=0$. Then, Tesla's profit function can be expressed by

$$
\Pi_{1}=\left(p_{1}-c_{1}\right) q_{1}+\sum_{j=2}^{3}\left(f_{j}+\left(r_{j}-c_{1}\right) q_{j}-m_{j}\right) x_{j},
$$

where $f_{j}(j=2,3)$ is the fixed-fee term to Tesla in the coopetition payment contract, $r_{j}(j=2,3)$ is the unit payment term to Tesla in the contract, $c_{j}(j=1,2,3,4)$ is the marginal cost, and $m_{j}(j=2,3)$ is the cost of forming and monitoring the alliance with Tesla. On the other hand, the profit function of firm $i(i=2,3,4)$ is expressed by

$$
\Pi_{i}=p_{i} q_{i}-c_{i} q_{i}\left(1-x_{i}\right)-\left(f_{i}+r_{i} q_{i}-m_{i}\right) x_{i}
$$

In addition, based on the results (specifically, Proposition 2) in Zhang and Frazier [22], an alliance between firm 1 and firm $i$ can be formed under the two-part tariff contract $\left(r_{i}, f_{i}\right)$ where

$$
=\frac{a \delta_{i}\left(1+\delta_{i}\right)\left(2+\delta_{i}\right)+c_{i}\left(2-\delta_{i}\right)\left(2-3 \delta_{i}+\delta_{i}^{2}-2 \delta_{i}^{3}\right)}{2\left(2-4 \delta_{i}+4 \delta_{i}^{2}-5 \delta_{i}^{3}+\delta^{4}\right)},
$$

$$
\begin{aligned}
& f_{i} \\
& =\lambda_{i}\left(\Pi_{i}^{A}-\Pi_{i}^{O}-m_{i}\right) \\
& -\left(1-\lambda_{i}\right)\left(\Pi_{1}^{A}-\Pi_{1}^{O}-m_{i}\right) \text { such that } \\
& \Pi_{1}^{A}=\left(p_{1}-c_{1}\right) q_{1}+\sum_{j=2}^{3} r_{j} q_{j} x_{j}, \\
& \Pi_{i}^{A}=p_{i} q_{i}+r_{i} q_{i} x_{i}, \quad i=2,3, \\
& \Pi_{1}^{O}=\left(p_{1}-c_{1}\right) q_{1}+\sum_{j \neq 1, i} r_{j} q_{j} x_{j}, \\
& \Pi_{i}^{O}=\left(p_{i}-c_{i}\right) q_{i}, \quad i=2,3,
\end{aligned}
$$

where $\lambda_{i}$ represents the bargaining power of firm 1 against firm $i\left(i=2\right.$,3) [24]. In the equations above, $\Pi_{i}^{A}$ represents firm $i$ 's profit before considering the fixed-fee payment $f_{i}$ and contracting cost $m_{i}$ in the alliance while $\Pi_{i}^{O}$ represents firm $i$ 's profit in the oligopoly market.

Lastly, due to the assumption of the rationality of decision makers and perfect information in the market, the best response functions under a simultaneous game setting are incorporated as constraints (see (5b) and (5c)), which represent the best strategy one should play given all others' actions [25]. Therefore, the mathematical formulation for this EV coopetition scenario for given alliance decisions, $\mathbb{P}_{n}\left(x_{2}, x_{3}, x_{4}\right)$, is presented as follows.

Problem $\mathbb{P}_{n}\left(x_{2}, x_{3}, x_{4}\right)$ is

$\max \Pi_{n}$

$$
\text { s.t. } \quad q_{1}-\left(p_{1}-c_{1}\right)+\sum_{j=2}^{3}\left(\left(r_{j}-c_{1}\right)-\left(p_{1}-c_{1}\right)\right) x_{j}
$$

$=0$,

$$
q_{i}-p_{i}+c_{i}\left(1-x_{i}\right)-\left(r_{i}-p_{i}\right) x_{i}=0
$$$$
i=2,3,4 \text {, }
$$

$$
q_{i} \geq 0, \quad i=1,2,3,4,
$$

for $n=1,2,3,4$.

By using $\mathbb{P}_{n}\left(x_{2}, x_{3}, x_{4}\right)$, we proceed the coopetition case study according to the following two-step approach.

Step 1 (alliance decision). First, each firm $n$ makes its decision of whether to form an alliance with Tesla or not (i.e., $x_{n}=1$ or 0 ). We note that all possible combinations of values for $x_{2}$, $x_{3}$, and $x_{4}$ reduce to the following four scenarios, given that $x_{4}=0$ :

$$
\left(x_{2}, x_{3}, x_{4}\right) \in\{(0,0,0),(1,0,0),(0,1,0),(1,1,0)\} .
$$

Step 2 (pricing decision). For each scenario in Step 1, each firm $n$ determines its pricing strategy via $\mathbb{P}_{n}\left(x_{2}, x_{3}, x_{4}\right)$ (i.e., each player tries to maximize its own profit $\Pi_{n}$ while 
TABLE 1: Factual data for the Tesla coopetition case.

\begin{tabular}{lccc}
\hline & Tesla Model S & Daimler Smart Fortwo & Toyota RAV4 EV \\
\hline${\text { Quantity sold in } 2013^{1}}^{1}$ & 18,650 & 923 & 1,096 \\
${\text { EV price } p_{i}}^{\text {Cost excluding powertrain }}{ }^{5}$ & $57,400^{2}$ & $17,890^{3}$ & $49,800^{4}$ \\
Powertrain cost w/o coopetition & & 10,050 & 30,050 \\
Powertrain cost w/t coopetition & 40,050 & 15,000 & 15,000 \\
EV substitutability $\delta_{i}{ }^{6}$ & 3,000 & 7,356 & 7,474 \\
Alliance monitoring cost $m_{i}$ (USD) & 3,000 & 0.159 & 0.068 \\
Alliance fixed payment $f_{i}$ (USD) & 1 & 515,123 & 805,300 \\
Assets (USD millions) & $1,200,000^{8}$ & $3,210,617.32^{9}$ & $8,475,411.32^{10}$ \\
Bargaining power against Tesla [24] & $2,416.93^{1}$ & $117,604.13^{11}$ & $336,957.57^{12}$ \\
\hline
\end{tabular}

${ }^{1}$ http://www.hybridcars.com/december-2013-dashboard/.

${ }^{2}$ http://www.teslamotors.com/models/design.

${ }^{3} \mathrm{http}: / /$ usnews.rankingsandreviews.com/cars-trucks/Smart_Fortwo/prices/.

${ }^{4}$ http://www.toyota.com/rav4ev/\#!/Welcome.

${ }^{5} \mathrm{http}: / /$ www.reuters.com/article/2012/11/05/tesla-results-idUSL1E8M51DA20121105.

${ }^{6} \mathrm{http}: / /$ online.wsj.com/news/articles/SB10001424127887323981304579079492902482638.

${ }^{7}$ http://www.economicswebinstitute.org/glossary/substitute.htm.

${ }^{8}$ http://files.shareholder.com/downloads/ABEA-4CW8X0/3039494247x0x727013/9885dd26-2e82-4052-b171-3685fd8150b3/ Q4'13\%20Shareholder\%20Letter.pdf.

${ }^{9}$ http://www.valuewalk.com/2013/06/how-tesla-motors-inc-tsla-is-helping-toyota-and-daimler/.

${ }^{10} \mathrm{http} / /$ www.sfgate.com/business/article/Tesla-signed-to-build-power-train-for-electric-2353819.php.

${ }^{11} \mathrm{http}: / /$ www.daimler.com/Projects/c2c/channel/documents/2432182_Daimler_2013_Annual_Financial_Report.pdf; http://www.ecb.europa.eu/stats/exchange/eurofxref/html/eurofxref-graph-usd.en.html.

${ }^{12} \mathrm{http}: / /$ www.toyota-global.com/investors/financial_result/2013/pdf/q4/summary.pdf.

satisfying equilibrium conditions of (5b) and (5c)). Since each maximization problem $\mathbb{P}_{n}\left(x_{2}, x_{3}, x_{4}\right)$ is related to others, the maximization problems become simultaneous games among firms (see Proposition 1 in [22]).

\section{Case Study: Coopetition with Tesla}

In this section, we present the numerical experiments under various scenarios. For the experiments, we primarily draw on the data set shown in Table 1.

4.1. Single-Period Coopetition Effect. A comparison of the profit for Tesla and its partners (Daimler and Toyota) with or without coopetition is illustrated in Figure 2 (retrieved from data in Online Supplement A in Supplementary Material available online at http://dx.doi.org/10.1155/2016/7210767). Although Tesla has to bear high monitoring costs when supervising and guiding powertrain component assembly in Daimler and Toyota, Tesla experiences a positive feedback from coopetition with Daimler and Toyota, gaining extra USD 18.21 million or a $6.80 \%$ increase in profit in its EV market by selling powertrain components to Daimler and Toyota. Moreover, such temporary strategic partnerships with Daimler and Toyota do not actually affect the production capacity for Tesla's model $\mathrm{S}$ and upcoming new versions. Tesla's factory in Fremont, Northern California, has the ability to potentially increase annual production to $35,000 \mathrm{EVs}$ until the beginning of 2016 [26], which is plenty to satisfy both Tesla's own sales targets and its partners' demand (see Section 4.2 for further discussion).

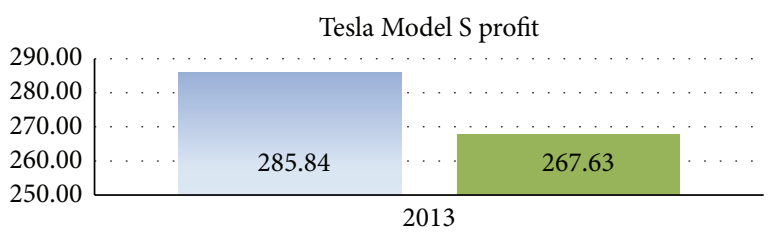

- Tesla Model S profit w/t coop. USD million

- Tesla Model S profit w/o coop. USD million

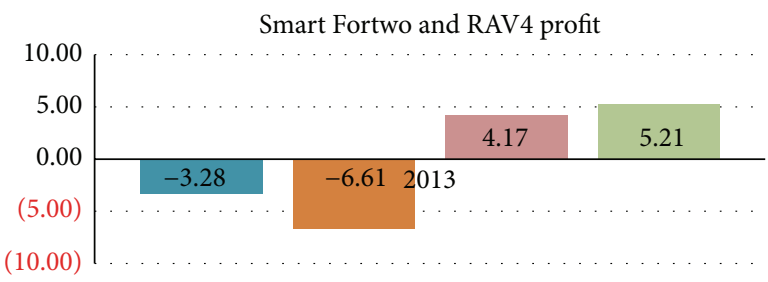

- Daimler Smart Fortwo profit w/t coop. USD million

- Daimler Smart Fortwo profit w/o coop. USD million

- Toyota RAV4 EV profit w/t coop. USD million

- Toyota RAV4 EV profit w/o coop. USD million

Figure 2: Coopetition effect on Tesla, Daimler, and Toyota.

On the other hand, the first-year of cooperation has different effects on Daimler and Toyota, respectively. Due to a low demand quantity in the US EV market and a low profit margin, Smart Fortwo has a bad sales and profit report. However, the cooperation alleviates the extent of loss for Smart from USD 6.61 million to USD 3.28 million. In other words, even though Daimler has to pay a substantial contract 

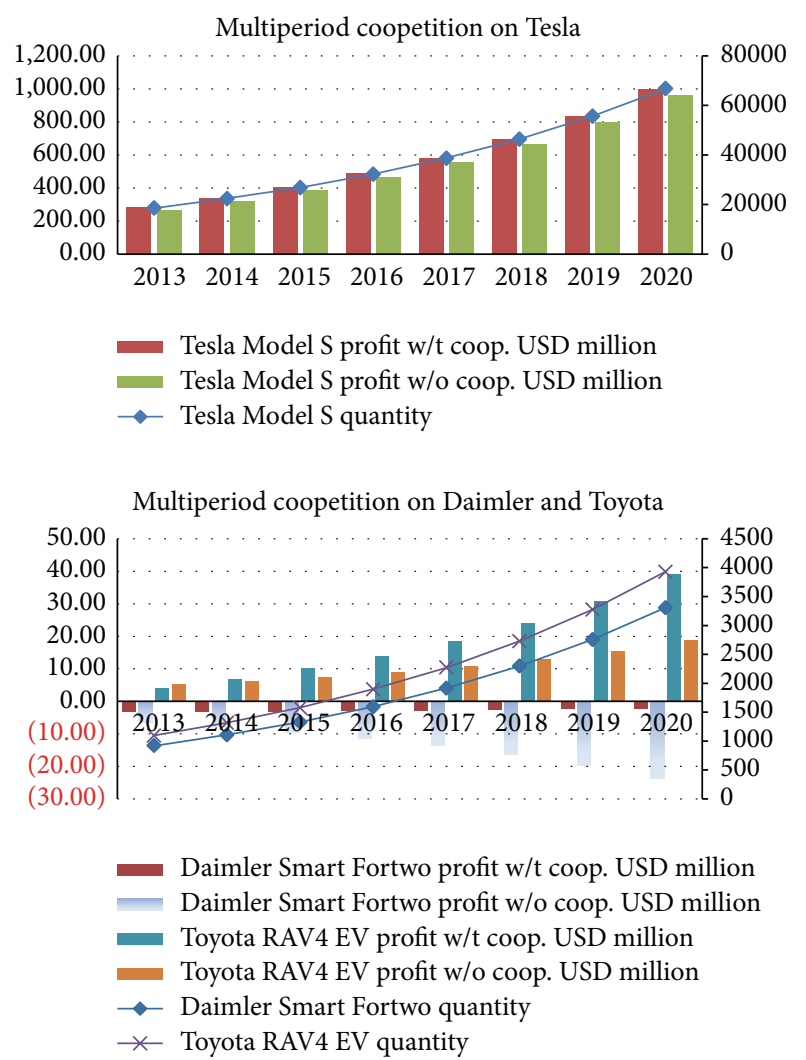

FIGURE 3: Coopetition effects over multiple periods.

fee to Tesla and cover monitoring costs in its own plants, coopetition results in USD 3.33 million savings for Daimler. However, the coopetition does not seem to be helpful to Toyota. The huge monitoring cost and fixed payment to Tesla actually offset the lower cost of powertrain components, reducing RAV4's total profit from USD 5.21 million to USD 4.17 million.

Therefore, coopetition may not be beneficial to all parties, and, furthermore, this lack of a benefit may result in a cessation of contracts in the near future. We remark that the expected increased annual quantity of units sold plays a key role in offsetting the outstanding fixed contract payment and monitoring costs. With a positive expectation of the US EV market, an annual estimated $20 \%$ increase in EV demand until 2020 [27] is a useful assumption when analyzing the multiperiod coopetition.

4.2. Multiperiod Coopetition Outlook through 2020. According to the estimate by the International Energy Agency [27], the US EV market will have an almost constant $20 \%$ annual increase in sales until 2020. Figure 3 (retrieved from data in Online Supplement B) illustrates the dynamic coopetition effects on each firm, respectively, by plotting sales quantity in lines and profit changes in bars. With the assumption of a constant $20 \%$ increase in annual sales and constant variable values, including monitoring cost, fixed and unit contract payments, and powertrain cost, coopetition can be beneficial to all parties. Tesla would experience a stable increase in profit through coopetition by selling powertrain components to Daimler and Toyota, whereas Toyota would benefit more than Daimler from the coopetition through increased annual sales. If the positive expectation for the EV market is met, coopetition can boost Toyota's profit with continuously growing annual sale. In later years, fixed costs such as fixed contract payments and monitoring costs become less substantial because the reduction in powertrain cost per EV from USD 15,000 to USD 7,474 is likely to lead to huge savings in production.

Daimler would also have a lesser loss under coopetition. Unlike Toyota which has a desirable marginal benefit from producing one extra RAV4 EV, Daimler's Smart Fortwo has too little profit to cover the fixed payments initially. However, Smart Fortwo's loss is gradually reduced through coopetition, unlike the situation where Daimler works alone and incurs a marginal loss for each extra Smart Fortwo produced alone. The reason why Daimler insists on producing EVs for the US market in spite of incurring continuous loss is because Daimler can enjoy federal grants for EV R\&D under the American Clean Energy and Security Act of 2009, and the quantity of EVs can meet part of the quota required to import internal-combustion cars to the US market [28].

However, there is a concern that Tesla may not be able to fulfill all the powertrain component requests from Toyota and Daimler in the near future due to Tesla's annual production capacity limit of 35,000 [26], which is much lower than 74,060 , the total sales projection for the three firms by 2020 . In fact, based on Tesla's existing factory capacity, it can only maintain coopetition with Daimler and Toyota concurrently until the beginning of 2016 since the total sales of the three are expected to reach 35,716 by the end of 2016 . Fortunately, Tesla's strategic planning department has foreseen a boom in the US EV market and a continuous demand for its powertrain components in the future and plans to invest USD 5 billion to build one "Gigafactory" and battery factories at possible sites in Arizona, Nevada, New Mexico, and Texas [29]. The purpose of the Gigafactory aims to provide more competent and lower cost powertrain components through heavy investment and streamlined manufacturing and assembling processes. Thus, coopetition is mutually beneficial to Tesla and its partners (i.e., Daimler and Toyota) in that Tesla can invest the extra money gained from coopetition on research, development, and demonstration (RD\&D) [27], whereas its partners may receive lower cost powertrain components as an outcome of that RD\&D.

4.3. Impact of the Three-Party Coopetition on Outsiders. In this section, we examine the economic impact of the coopetition discussed on outsiders. Figure 4 illustrates the general US EV market share in 2013. Based on sales history [30], Nissan and General Motors have been dominant in the US EV market for years. On the other hand, Tesla has created a sales miracle by selling 18,650 Model S vehicles and taking up to $20.59 \%$ of the US EV market. According to the coopetition model given in Section 3, the US market share can be simplified in Table 2.

In fact, the majority of Toyota's EV market share comes from another series named Prius. According to 2013 Toyota 
TABLE 2: US EV market share segments by firms in 2013.

\begin{tabular}{lcc}
\hline Firm number & Actual firm & Market share \\
\hline Firm 1 & Tesla & $20.59 \%$ \\
Firm 2 & Daimler & $0.61 \%$ \\
Firm 3 & Toyota & $7.18 \%$ (RAV4 EV 0.80\%) \\
Firm 4 & Outsider & $71.62 \%$ \\
\hline
\end{tabular}

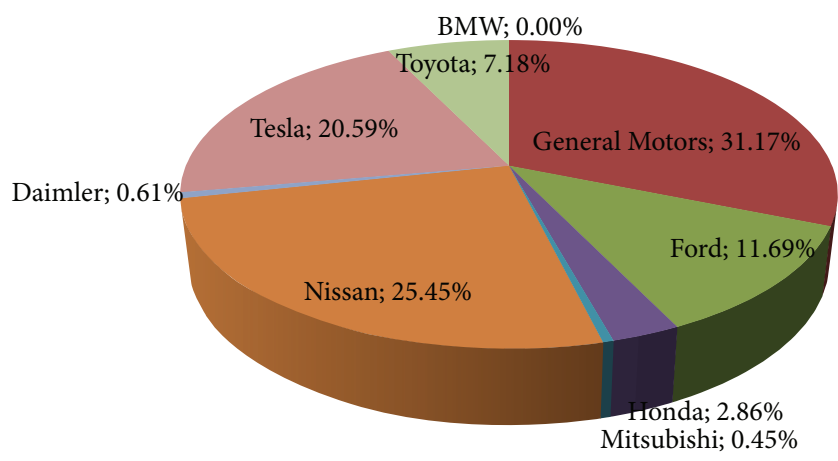

FIgURE 4: The US EV market share in 2013 [35]. This figure is taken from http://energypolicyinfo.com/2013/07/another-record-monthof-electric-vehicle-sales/.

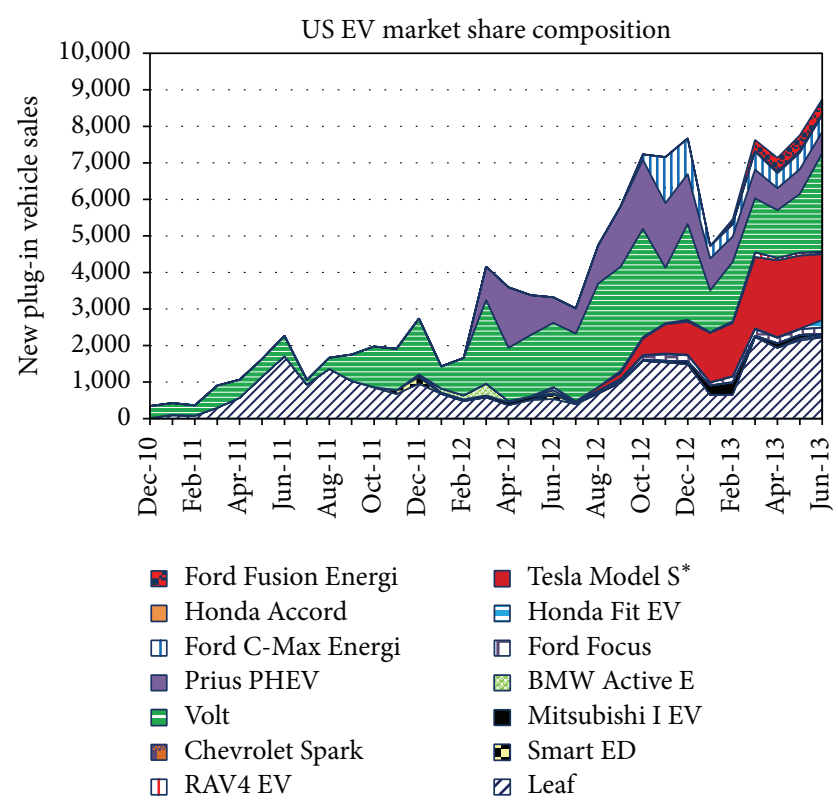

FIGURE 5: The US EV market share composition by firms [31].

EV sales data [31], the RAV4 EV represented 11.1\% of Toyota's total EV sales in the US. Hence, the market share of the RAV4 EV is $0.80 \%$ of the 2013 US EV market. Therefore, the coopetition between Tesla and Daimler/Toyota took up to $22 \%$ of the total US market in 2013. Based on the fact that the outsider including hybrid EV manufacturers has the dominant market share in the US EV market currently, coopetition in this discussion may not affect the outsider in terms of market share and price. Figure 5 (retrieved from Online Supplement C) illustrates the general trend that each firm's EV sales change steadily reflecting the demand for the whole EV market, more than rivals' marketing strategies. Moreover, with US clean energy policies such as federal tax incentives and tax grants for EV purchase and EV R\&D, respectively [28], increases in both demand and supply can be anticipated, resulting in greater EV sales in general.

In addition, the future of the $\mathrm{EV}$ market is positive with an annual increase of $20 \%$ foreseen until 2020 [27]. Hence, given a booming US EV market, the outsider may focus more on designing and manufacturing its own versions of EVs, instead of being concerned about the impact of coopetition, because the demand for the outsider's EV is likely to be so strong that its factory productivity may not be able to fulfill all the orders. However, since Tesla has an ambitious strategic "Gigafactory" plan to expand its productivity to 500,000 annually in 2020 [32] and anticipated total US EV sales is about 385,000 in 2020, the US EV market may undergo a revolution. Although meeting the estimated annual productivity of 500,000 by 2020 includes various provisions such as powertrain manufacture, gear assembly, and Tesla EV brand development, Tesla could still take significant market share in 2020 as planned. Moreover, with the extra revenue generated by the ongoing Tesla-Daimler and Tesla-Toyota coopetitions, Tesla will have stronger profitability which may have more of an impact than outsiders anticipate. Therefore, coopetition in Tesla's case might follow the traditional and theoretical way illustrated by Brandenburger and Nalebuff [1] and Bengtsson and Kock [15] of expanding the pie first and then splitting the pie afterward.

4.4. Possible Cessation of Coopetition. A coopetition strategic partnership may be terminated because at least one participant is much better off developing alone than extending the period of partnership [1]. According to Figure 2, Daimler's Smart Fortwo had negative figures in the annual report under coopetition with Tesla. Although the marginal costs of the powertrain components offered by Tesla to Daimler and Toyota, respectively, are similar $\left(r_{2}=7,356, r_{3}=7,474\right)$, the powertrain components represent $41.1 \%$ of the price of one Smart Fortwo, but only $15.0 \%$ of the price of one Toyota RAV4 $\mathrm{EV}$, while Tesla's own branding powertrain components represent $5.22 \%$ of the Model S price. Hence, a higher percentage cost of powertrain components not only diminishes the marginal benefit of producing extra Smart Fortwos, but also fails to cover the fixed contract payment and monitoring costs. Hence, Daimler's strategic goal in coopetition with Tesla might be to initially analyze how Tesla manufactures, streamlines, and assembles powertrain components and then study and integrate that process into Daimler's own manufacturing line. Therefore, Daimler's strategy may be similar to the case mentioned in Section 1 in which Borders launched its own online supply chain system after collaborating with Amazon.com. In order to quantify Daimler's strategy, a mathematical model incorporating this aspect of technological learning in the manufacturing industry is considered.

A mathematical model incorporating the technological learning curve should be quantified in such a way that it can accurately anticipate the correct timing of the ending of the coopetition between Tesla and Daimler. The most common 


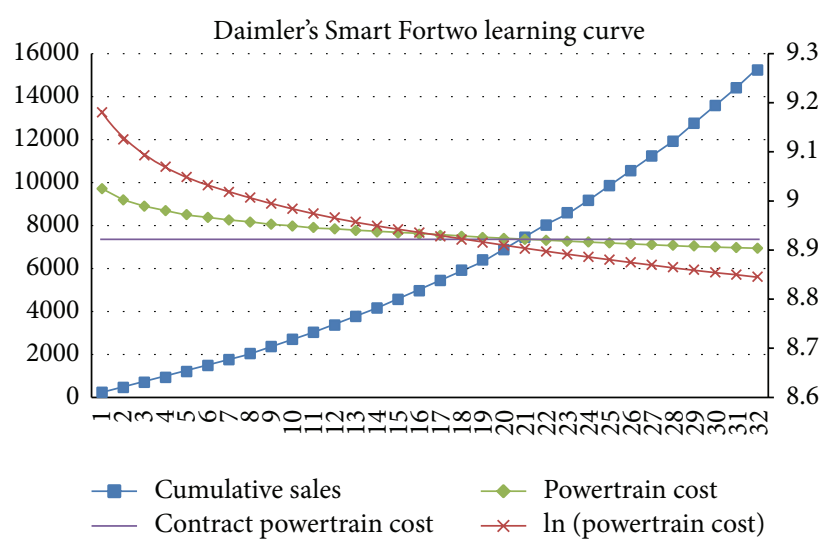

FIgURE 6: Daimler's Smart Fortwo learning curve.

learning curve estimation technique is $c_{t}=c_{1} X_{t}^{-\alpha}$ or its equivalent $\operatorname{logarithmic}$ form, $\ln c_{t}=\ln c_{1}-\alpha \ln X_{t}$, where $c_{t}$ is the powertrain cost in period $t, t$ is a quarterly index, $c_{1}$ is the original powertrain cost in the first quarter, $X_{t}$ is the cumulative number of powertrains received from Tesla, and $\alpha$ is the elasticity of a unit with respect to the cumulative volume [33]. We note that $\alpha$ has different values in different industry sectors, and, in this analysis, we set the value of $\alpha$ as 0.08 by adopting the norm for the machinery industry sector [33]. Based on Daimler's Smart Fortwo annual sales, Figure 6 (retrieved from data in Online Supplement D) presents the learning curve over 32 periods.

If Daimler's Smart Fortwo cumulative sales increase continuously, a desirable decrease in powertrain cost could develop, although it might still be higher than the contract powertrain cost at the early stage. However, as time goes by with continuously increasing Smart Fortwo sales, the ultimate powertrain component cost incorporating the learning curve could be lower than the one offered by Tesla, with the theoretical breaking point at period 21, which corresponds to the first quarter of 2018. Therefore, it can be estimated that the cessation of the coopetition partnership between Daimler and Tesla might possibly occur in early 2018. However, in order to keep the learning curve active, Daimler has to obtain the authorization to use Tesla's technology legitimately or invest in this technology independently and redesign its plants to reach Tesla's plant standards.

Figure 7 illustrates the estimated Smart Fortwo powertrain expenditure and corresponding profit from 2018 to 2020, based on the sales forecast in Figure 3. The breakeven point of investing in building an in-house version of powertrain technology versus leasing the technology from Tesla and redesigning the plants would be USD 53,491,069, which is the extra cost difference considering cumulative expenditure and cumulative profit, if Daimler targets it as a two-year project. Tesla's plan to expand its factory production from 21,500 per year in 2013 to 500,000 per year by 2020 through investing five billion US dollars $[26,32]$ would represent an average investment per EV of USD $(5,000,000,000 /(500,000-21,500))=$ 10,449 . By referring to this figure, the investment required to expand the production to an extra 3,307 EVs per year through

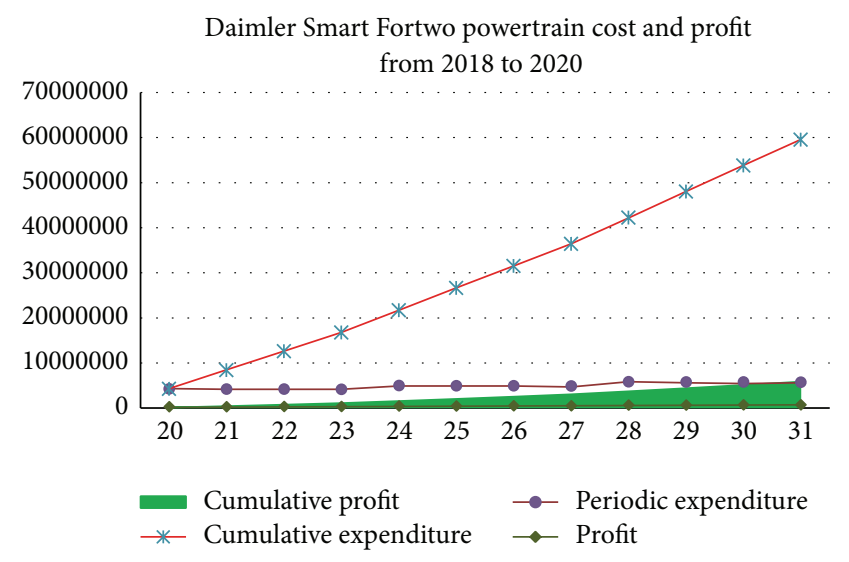

FIGURE 7: Daimler's Smart Fortwo powertrain cost and profit.

coopetition with Tesla would be $10,449 \times 3,307=34,555,903$, less than $53,491,069$. These two numbers make sense in that Daimler, despite being a traditional car-making giant, would have extra expenses to recruit EV-specialized talent and invest in EV R\&D to enter the EV market; Tesla, on the other hand, having core employees and the key technology already available can achieve its goals with less expenditure.

In fact, Daimler has started to reconsider the partnership with Tesla. In order to keep Daimler's EV competitive in the US EV market and less dependent on Tesla's powertrain supply, Daimler has made the decision to develop some types of EVs in house, with the help of technology giant Robert Bosch [30]. On the other hand, bearing in mind the economic theory that a firm may not have enough incentive to invest in components which make up only a small percentage of the total cost of its products [25], Toyota may have less motivation to invest in developing its own version of powertrain technology and manufacturing plants, considering that the powertrain cost accounts for Daimler, Toyota, and Tesla which are $41.1 \%, 15.0 \%$, and $5.22 \%$ of the cost of one EV, respectively. Instead, Toyota has been spending money on EV designs and internal decorations from RAV1 to RAV4 [34]. Such a strategy actually brings a unique competency in terms of profit and market exposure for RAV4 in the US EV market.

\section{Managerial Insights and Conclusion}

In this paper, through the analysis of a horizontal supply chain model where high-cost firms and low-cost firms coexist, we came to the conclusion that coopetition among firms depends on several factors, including firms' bargaining power, substitutability of goods, contract payments, friction costs of alliances, and the learning curve effects. The discussion of coopetition centered around the in-depth Tesla case study leads to a proposal of a conceptual framework for coopetition between giants. With collected data including the contracts between Tesla and Daimler/Toyota, the US $\mathrm{EV}$ market share, and each firm's strategies, we analyze and anticipate the short- and long-term effects of coopetition on participant firms, outsider firms, and the market in 
general. With background understanding that business is a combination of war and peace, firms should seek appropriate partners, including rivals, to pursue opportunities to enter new markets. The Tesla's case study of this paper illustrates some desirable outcomes of coopetition in that Daimler and Toyota have successfully entered the US EV market by buying in lower-cost powertrain components and Tesla has been able to expand its "Gigafactory" in the future by gaining extra revenues from a coopetition contract. Hence, the chance for firms to achieve their own specific goals through collaboration motivates them to develop strategic partnerships with others, despite still having to compete with each other at the finished-goods level [15]. Moreover, by analyzing the dynamic multiperiod coopetition between Tesla and Daimler/Toyota, we are able to illustrate the changing effects of coopetition period by period and thereby suggest to both participant firms and outsiders the best way to respond to market changes. In general, high-cost firms, in a coopetition partnership, may have diminishing marginal returns because of learning curve effects and technology reformation. Hence, high-cost firms, such as Daimler and Toyota, have to choose the correct time to cease coopetition, so as to become more competent in producing their own brand products and less reliant on buying in key workin-process parts. On the other hand, outsiders, even those with a current dominant market share, ought to pay close attention to their rivals' coopetition partnerships, because the extra liquidity generated from coopetition may allow rivals to boost their productivity and grab extra market share. On top of that, a unique feature of the case study in this paper is two concurrent bilateral coopetition partnerships. Unlike previous research which has only investigated one bilateral coopetition partnership between two firms, we illustrate differences in dependent variables such as contract payments, monitoring costs, and unit payments given differences in firms' bargaining powers, substitutability of goods, and rates of learning curves. Thereafter, the differences of additional factors due to the unique situation of each participant firm may generate different decisions about whether to renew or extend coopetition partnerships and the timings of those actions. The low-tech participant firm, whose buy-in component cost is proportionally higher and whose profit per unit is lower, should quit coopetition earlier to accelerate technological improvement based on its own particular learning curve effect. On the other hand, a participant firm, who can enjoy the low cost of the buy-in parts continuously and make a desirable profit through coopetition in the long run, might be reluctant to quit the partnership. Moreover, theoretical mathematical models of coopetition that do not consider capacity limits, in terms of the market demand capacity and individual firm's productivity, risk resulting in the unlimited expansion of collaborations and finally unoptimistic early cessation of coopetition. This paper, with thorough constraints such as each firm's strategic planning, anticipated market growth, and relevant policy influences, is able to illustrate the timing of the decision as to whether to renew or terminate a coopetition partnership.

Opportunities for follow-up research abound. One approach is to make the mathematical models of coopetition more realistic by investigating partial coopetition partnerships. In real business, a firm is unlikely to solely depend on another firm's exports, especially for parts related to key technologies. Hence, a more realistic coopetition would be one in which the high-cost firm may sign a contract to order a volume of parts from a low-cost one for a portion of the products while producing an in-house additional volume of the product or a similar but differentiated series of products using self-developed technologies. For example, Toyota has been importing Tesla's powertrain components for its RAV4 EVs while producing the Prius with its own batteries, whereas Daimler has signed contracts with Robert Bosch and Tesla concurrently for its A Class EVs and Smart Fortwos [30]. Another approach which makes coopetition more realistic is a collaboration contract which agrees on orders of multiple parts. Nowadays, the mathematical models dealing with a single part transferred from a low-cost firm to a high-cost one are too narrow to analyze the complex business world. Multiple-part coopetition would involve an additional set of variables for each product, including different contract payments, different unit payments, and different monitoring costs. For example, Daimler has signed a contract with Tesla ordering different versions of powertrain components for its A Class, B Class, and Smart Fortwo EVs, respectively. Hence, a more complex, but thorough coopetition model would be more useful when estimating the timing of the renewal and cessation of coopetition and investigating the responses of participant firms and outsiders.

\section{Conflict of Interests}

The authors declare that there is no conflict of interests regarding the publication of this paper.

\section{Acknowledgment}

Sang Hwa Song's work was supported by the Incheon National University Research Grant in 2014.

\section{References}

[1] A. M. Brandenburger and B. J. Nalebuff, Co-Opetition, Doubleday, New York, NY, USA, 1996.

[2] H. Gurnani, M. Erkoc, and Y. Luo, "Impact of product pricing and timing of investment decisions on supply chain coopetition," European Journal of Operational Research, vol. 180, no. 1, pp. 228-248, 2007.

[3] A. Satariano and L. King, "Apple sticks with Samsung for IPhone chip, IFixit says," Bloomberg, 2013, http://www.bloomberg.com/ news/2013-09-20/apple-sticks-with-samsung-for-iphone-chipifixit-says.html.

[4] T. Worstall, Samsung Loses Another Apple Patent Case This Time in Germany, Forbes, 2013, http://www.forbes.com/sites/timworstall/2013/11/22/samsung-loses-another-apple-patent-casethis-time-in-germany/.

[5] G. Casseres, "Group versus group: how alliance networks compete," Harvard Business Review, vol. 72, pp. 62-74, 1994.

[6] M. Kodama and T. Shibata, "Research into ambidextrous $\mathrm{R} \& \mathrm{D}$ in product development-new product development at a 
precision device maker: a case study," Technology Analysis and Strategic Management, vol. 26, no. 3, pp. 279-306, 2014.

[7] D. R. Gnyawali and B.-J. Park, "Co-opetition between giants: collaboration with competitors for technological innovation," Research Policy, vol. 40, no. 5, pp. 650-663, 2011.

[8] K. Corbin, "Borders Breaks Off 7-Year Amazon Partnership," ITBusinessEdge, 2008, http://www.internetnews.com/ec-news/ article.php/3749336/Borders+Breaks+Off+7Year+Amazon+ Partnership.htm.

[9] USDOT, “Transportation's roles in reducing U.S. greenhouse gas emissions," U.S. Department of Transportation Report to Congress, U.S. Department of Transportation, 2010.

[10] Tesla, "Using Energy Efficiency," Tesla Motors Inc, 2014, http:// www.teslamotors.com/goelectric/efficiency.

[11] IEA, Energy Statistics Manual, International Energy Agency (IEA), Paris, France, 2005.

[12] C. Squatriglia, "Tesla Motors Joins Daimler on a Smart EV," WIRED, January 2009, http://www.wired.com/autopia/2009/ 01/tesla-motors-jo/.

[13] Toyota, RAV4 2015, Toyota, 2013, http://www.toyota.com/rav4/ \#!/Welcome.

[14] J. R. Harbison and P. J. Pekar, Smart Alliances: A Practical Guide to Repeatable Success, Jossey-Bass, San Francisco, Calif, USA, 1998.

[15] M. Bengtsson and S. Kock, "Cooperation and competition in relationships between competitors in business networks," The Journal of Business \& Industrial Marketing, vol. 14, no. 3, pp. 178194, 1999.

[16] S. D. Pathak, Z. Wu, and D. Johnston, "Toward a structural view of co-opetition in supply networks," Journal of Operations Management, vol. 32, no. 5, pp. 254-267, 2014.

[17] R. C. Sampson, "R\&D alliances and firm performance: the impact of technological diversity and alliance organization on innovation," The Academy of Management Journal, vol. 50, no. 2, pp. 364-386, 2007.

[18] J. H. Dyer and H. Singh, "The relational view: cooperative strategy and sources of interorganizational competitive advantage," Academy of Management Review, vol. 23, no. 4, pp. 660-679, 1998.

[19] T. M. Jorde and D. J. Teece, "Innovation and cooperation: implications for competition and antitrust," Journal of Economic Perspectives, vol. 4, no. 3, pp. 75-96, 1990.

[20] D. Granot and S. Yin, "Competition and cooperation in decentralized push and pull assembly systems," Management Science, vol. 54, no. 4, pp. 733-747, 2008.

[21] M. Nagarajan and G. Sošić, "Stable farsighted coalitions in competitive markets," Management Science, vol. 53, no. 1, pp. 29-45, 2007.

[22] J. Zhang and G. V. Frazier, "Strategic alliance via co-opetition: supply chain partnership with a competitor," Decision Support Systems, vol. 51, no. 4, pp. 853-863, 2011.

[23] X. Vives, Oligopoly Pricing-Old Ideas and New Tools, MIT Press, Cambridge, UK, 1999.

[24] H. Gersbach and H. Haller, "Bargaining power and equilibrium consumption," Social Choice and Welfare, vol. 33, no. 4, pp. 665690, 2009.

[25] H. R. Varian, Intermediate Microeconomics: A Modern Approach, W. W. Norton \& Company, New York, NY, USA, 2010.
[26] A. Ingram, “Tesla to add production capacity for 35,000 more electric cars," The Washington Post, 2013, http://www.washingtonpost.com/cars/tesla-to-add-production-capacity-for-35000more-electric-cars/2013/12/18/35fc60f8-6822-11e3-997b-9213b17dac97_story.html.

[27] IEA, Global EV Outlook-Understanding the Electric Vehicle Landscape to 2020, International Energy Agency (IEA), Paris, France, 2013.

[28] IRS, “Internal Revenue Bulletin: 2009-48," Internal Revenue Service, 2009, http://www.irs.gov/irb/2009-48_IRB/ar09.html.

[29] M. Ramsey, "Tesla plans $\$ 5$ billion battery factory," The Wall Street Journal, 2013, http://online.wsj.com/news/articles/ SB10001424052702304709904579407473494212500.

[30] D. King, "Despite Tesla Tie, Daimler Moving EV Work InHouse," Edmunds AutoObserver, 2011, http://www.edmunds .com/autoobserver-archive/2011/04/despite-tesla-tie-daimlermoving-ev-work-in-house.html.

[31] EDTA, "Electric Drive Sales Dashboard," Electric Drive Transportation Association (EDTA), 2014, http://electricdrive.org/ index.php?ht=d/sp/i/20952/pid/20952.

[32] D. C. Jaclyn Trop, “Tesla plans $\$ 5$ billion battery factory for mass-market electric car," The New York Times, 2013, http:// www.nytimes.com/2014/02/27/automobiles/tesla-plans-5-billion-battery-factory-for-mass-market-electric-car.html?_r=0.

[33] P. Pramongkit, T. Shawyun, and B. Sirinaovakul, "Analysis of technological learning for the Thai manufacturing industry," Technovation, vol. 20, no. 4, pp. 189-195, 2000.

[34] Toyota, Toyota Financal Report 2013, Toyota, 2014, http://www .toyota-global.com/investors/financial_result/2013/pdf/q4/summary.pdf.

[35] EPIC, "Another Record Month of Electric Vehicle Sales," Energy Policy Information Centre (EPIC), 2013, http://energypolicyinfo.com/2013/07/another-record-month-of-electric-vehiclesales/. 


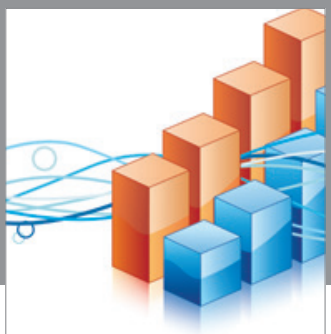

Advances in

Operations Research

vatem alat4

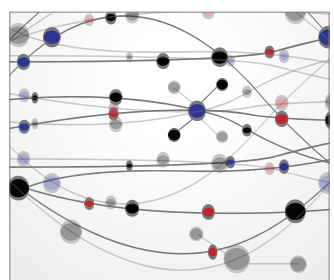

\section{The Scientific} World Journal
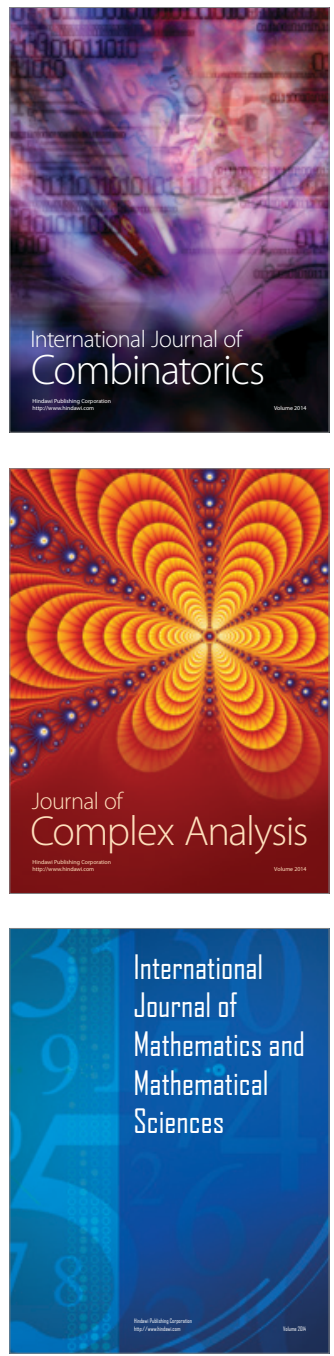
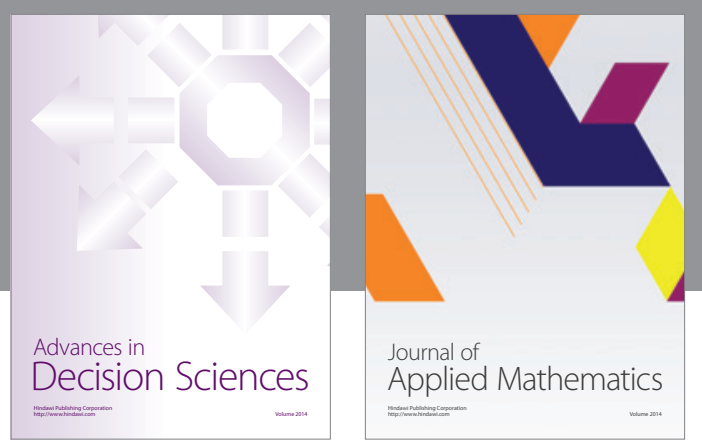

Algebra

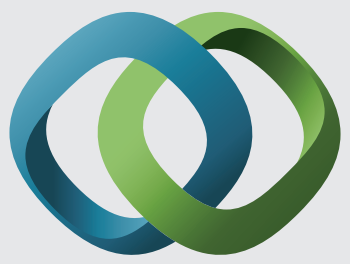

\section{Hindawi}

Submit your manuscripts at

http://www.hindawi.com
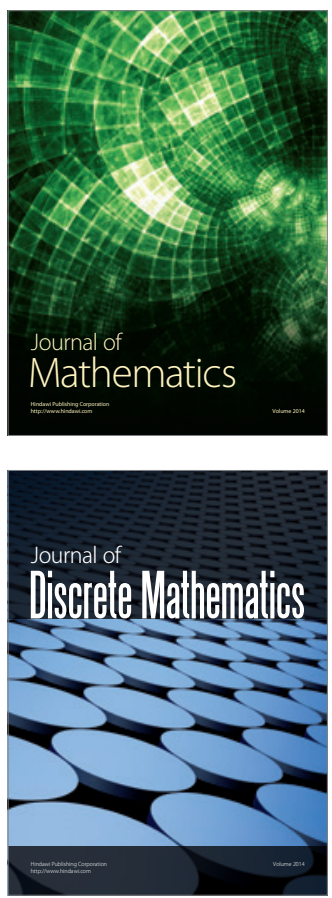

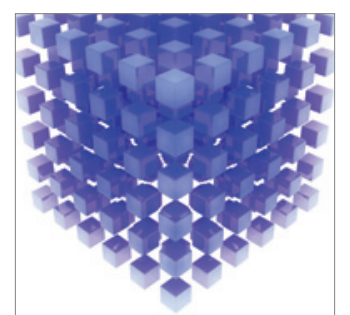

Mathematical Problems in Engineering
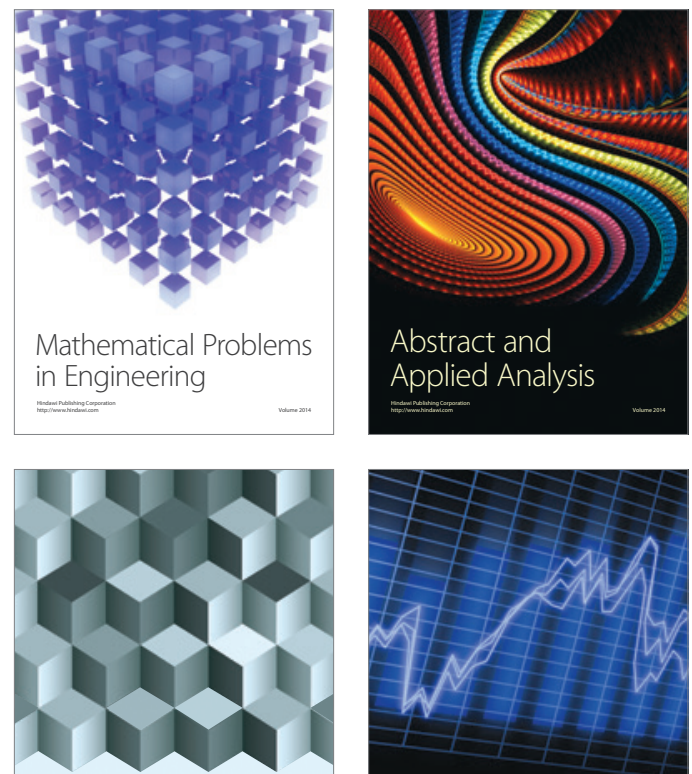

Journal of

Function Spaces

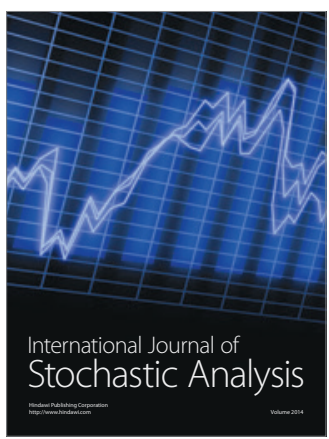

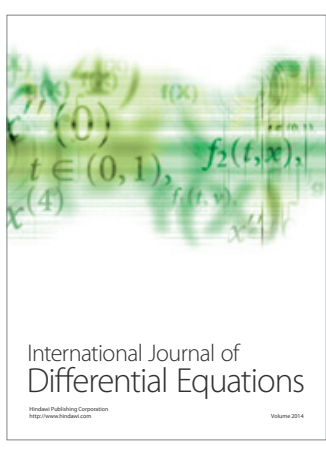
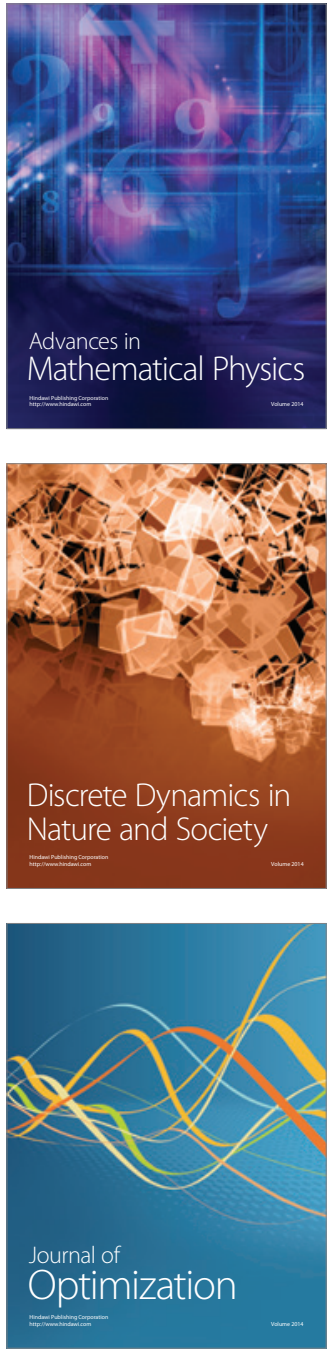